\title{
Upper Airway Mechanics
}

\author{
Johan A. Verbraecken Wilfried A. De Backer \\ Department of Pulmonary Medicine, Antwerp University Hospital and University of Antwerp, \\ Edegem, Belgium
}

\section{Key Words}

Central sleep apnoea - Cheyne-Stokes breathing • Obesity

hypoventilation syndrome $\cdot$ Obstructive sleep apnoea

\begin{abstract}
This review discusses the pathophysiological aspects of sleep-disordered breathing, with focus on upper airway mechanics in obstructive and central sleep apnoea, CheyneStokes respiration and obesity hypoventilation syndrome. These disorders constitute the end points of a spectrum with distinct yet interrelated mechanisms that lead to substantial pathology, i.e. increased upper airway collapsibility, control of breathing instability, increased work of breathing, disturbed ventilatory system mechanics and neurohormonal changes. Concepts are changing. Although sleep apnoea is considered more and more to be an increased loop gain disorder, the central type of apnoea is now considered as an obstructive event, because it causes pharyngeal narrowing, associated with prolonged expiration. Although a unifying concept for the pathogenesis is lacking, it seems that these patients are in a vicious circle. Knowledge of common patterns of sleep-disordered breathing may help to identify these patients and guide therapy.
\end{abstract}

Copyright $\odot 2009$ S. Karger AG, Basel

Previous article in this series: 1. Riha RL: Genetic aspects of the obstructive sleep apnoea/hypopnoea syndrome - is there a common link with obesity? Respiration 2009;78:5-17.

\section{Introduction}

In the last decades our understanding of the mechanisms leading to sleep disordered breathing has been steadily improved, with most studies being focused on upper airway patency and ventilatory control mechanisms during sleep. Instability of the breathing pattern can go along with an increase in upper airway resistance, increased collapsibility of the upper airway and discoordination of local reflex mechanisms, and can cause obstructive apnoeas. Unstable and irregular breathing in itself can lead to periodicity and central apnoeas. The type of respiratory event (central or obstructive) may be determined by upper airway characteristics and by the synchronism between upper airway muscles and respiratory muscles. In obese subjects, respiratory system mechanics can become disturbed, isolated or in association with upper airway pathology, and obesity hypoventilation syndrome (OHS) will develop. The Task Force of the AASM [1] states that there are common pathogenic mechanisms for obstructive apnoea syndrome (OSA), central apnoea syndrome (CSA), sleep hypoventilation syndrome and Cheyne-Stokes respiration (CSR). In this review we address how these mechanisms lead to sleep-disordered breathing. It was preferred to discuss them separately although they could be placed under the common heading of 'sleep-disordered breathing syndrome'.

\section{KARGER \\ Fax +4161306 1234 E-Mail karger@karger.ch} www.karger.com
(C) 2009 S. Karger AG, Basel 0025-7931/09/0782-0121\$26.00/0

Accessible online at: www.karger.com/res
Johan Verbraecken, MD, $\mathrm{PhD}$

Department of Pulmonary Medicine

Antwerp University Hospital, Wilrijkstraat 10

BE-2650 Edegem, Antwerp (Belgium)

Tel. +32 3821 3537, Fax +32 3821 4447, E-Mail johan.verbraecken@uza.be 


\section{Obstructive Sleep Apnoea}

OSA is characterised by recurrent episodes of partial or complete upper airway collapse during sleep. The collapse is highlighted by a reduction in or complete cessation of airflow despite ongoing inspiratory efforts. Due to the lack of adequate alveolar ventilation that results from the upper airway narrowing, oxygen saturation may drop and partial pressure of $\mathrm{CO}_{2}$ may occasionally rise. The events are mostly terminated by arousals. Clinical consequences are excessive daytime sleepiness related to the sleep disruption [2].

\section{Pathogenesis}

The narrowing or occlusion of the upper airway (UA) during sleep has been attributed to several factors (table 1). An abnormal anatomy of the UA, pathological and insufficient reflex activation of UA dilator muscles and increased collapsibility of the passive UA have all been demonstrated to occur and contribute to the UA collapse. More recently, it was also shown that UA collapse occurs during the terminal phase of the expiration preceding the apnoea. We recently could confirm this latter finding and obtain some preliminary indications that modelling of the expiratory phase may be worthwhile in predicting the collapse and the outcome of some UA interventions $[2,3]$.

\section{Abnormal Anatomy of the UA}

There are many studies indicating that the upper airway cross sectional area is smaller in patients with obstructive sleep apnoea. The narrowing of the upper airway, when studied during wakefulness, is often seen at the retropalatal and retroglossal area. Moreover, the configuration of the airway in OSA patients is different from normal controls with an anterior-posterior configuration [4, 5]. In the airway of normal controls, a horizontal configuration is seen with the major axis in the lateral direction. During the inspiratory phase little narrowing is seen, suggesting that the activation of the upper airway dilator muscles accurately compensates for the negative intra-luminal pressures. In apnoeic patients there was even some more enlargement during inspiration, possibly due to an even more increased UA muscle dilator activity. During expiration, airway calibre initially increases, due to the positive intra-luminal pressure, again more pronounced in the apnoeic patients, which present with the more distensible airways. However, at the end of the expiration, the airways narrow significantly and this narrowing is most
Table 1. Factors promoting upper airway collapse

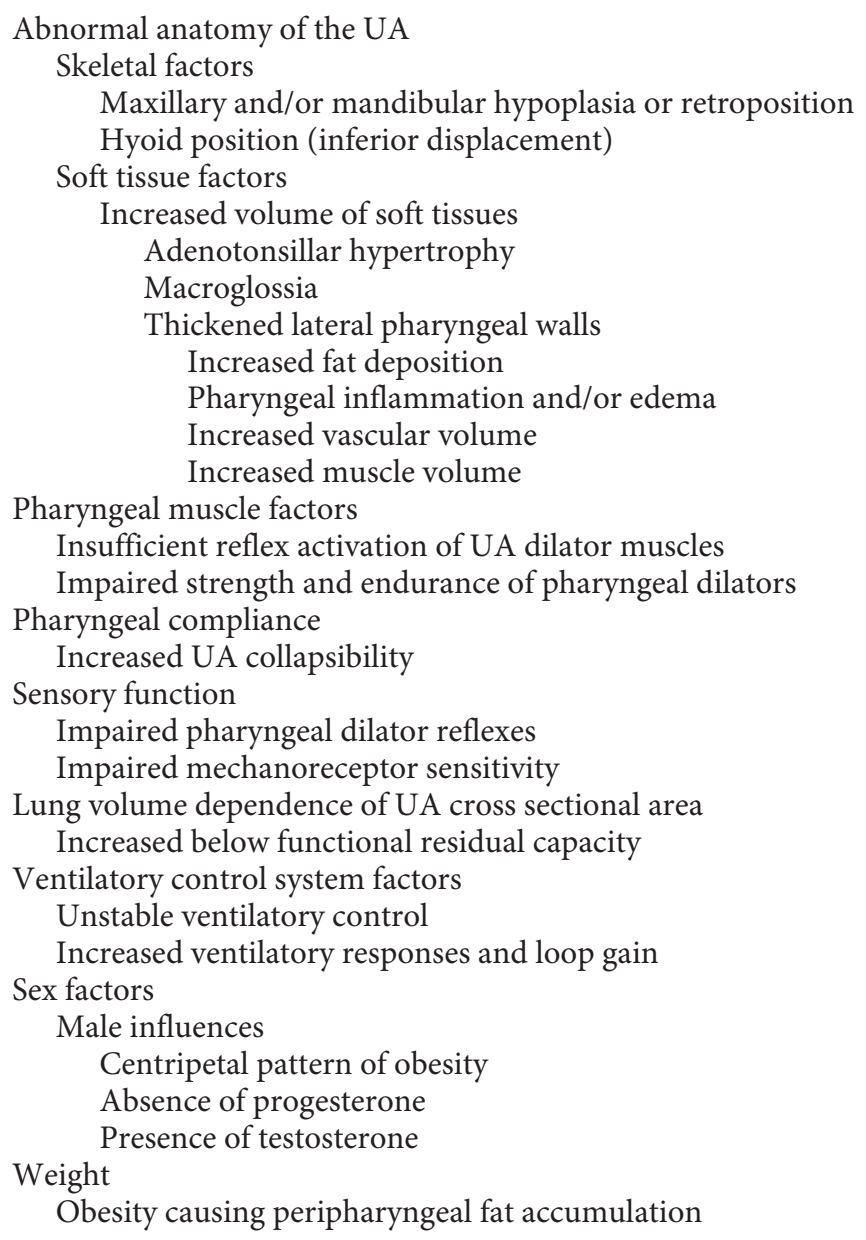

pronounced in OSA patients. It becomes clear already from these studies, performed during wakefulness, that narrowing of the UA is most critical at the end of the expiration. Beyond narrowing of the airway by the lateral pharyngeal walls, also tonsillar enlargement, enlargement of the uvula and tongue enlargement contribute to the occlusion of the upper airway during sleep [6]. With more detailed MRI techniques, it could be demonstrated that soft tissue enlargement predicts upper airway collapse. The volume of the tongue and the lateral walls were shown to be an independent risk factor for sleep apnoea [7]. Also ultrafast MRI imaging during sleep has confirmed these abnormalities. The variations in the velopharyngeal area during the respiratory cycle was greater in apnoeic patients than in controls and this was even more pronounced during sleep, suggesting an increased compliance of the velopharynx in these patients [8]. 
Insufficient Reflex Activation of UA Dilator Muscles

As already seen in the imaging studies, upper airway dilator muscle activation in OSA patients is quite adequate and even intensified during wakefulness. Several studies have confirmed this $[9,10]$. This activation is mainly due to reflex activation provoked by negative intra-pharyngeal pressures that are more pronounced in OSA patients due to the smaller airway. This reflex is quite active during wakefulness but significantly declines during sleep. Especially during NREM sleep, this negative pressure reflex is substantially diminished or lost completely [11]. Studies of genioglossal muscle activity suggest that patients with OSA have a much greater reduction in the genioglossal EMG than normal subjects [12]. Due to the loss of this compensatory reflex activation of the UA dilator muscles, the UA of OSA patients may significantly narrow during inspiration when asleep. These mechanisms have been described before as the 'balance of forces' model (fig. 1). It is likely that a combination of upper airway mechanical loads and disturbances in neuromuscular mechanisms account for the pathogenesis of OSA. For example, in a group of OSA subjects, one third of the variability in OSA severity was ascribed to mechanical loads, suggesting that neuromuscular mechanisms accounted for the remaining two thirds $[13$, 14].

\section{Increased UA Collapsibility}

Increased airway collapsibility significantly contributes to the UA collapse in OSA patients. Increasing levels of upper airway collapsibility lead to greater degree of airflow obstruction [15]. UA collapsibility can be determined from pressure-flow curves: the nasal mask pressure below which the upper airway closes can be considered as the critical closing pressure (Pcrit). The pressure flow relationship is dependent on the position of the patient and the sleep stage. Abbreviated methods have been developed to measure Pcrit more conveniently during sleep [16]. Also negative pressure pulses have been applied to measure UA collapsibility. It was demonstrated that collapsibility measured during wakefulness using negative pressure pulses correlates significantly with collapsibility during sleep [17]. Interestingly, pharyngeal collapsibility is influenced by abnormal craniofacial and soft tissue features. A significant correlation was found between Pcrit and soft palate length, the distance from the hyoid bone to the posterior pharyngeal wall and the distance from the hyoid bone to the posterior nasal space [18]. In obese patients Pcrit was related to the soft palate length, in non-obese patients the Pcrit was determined by

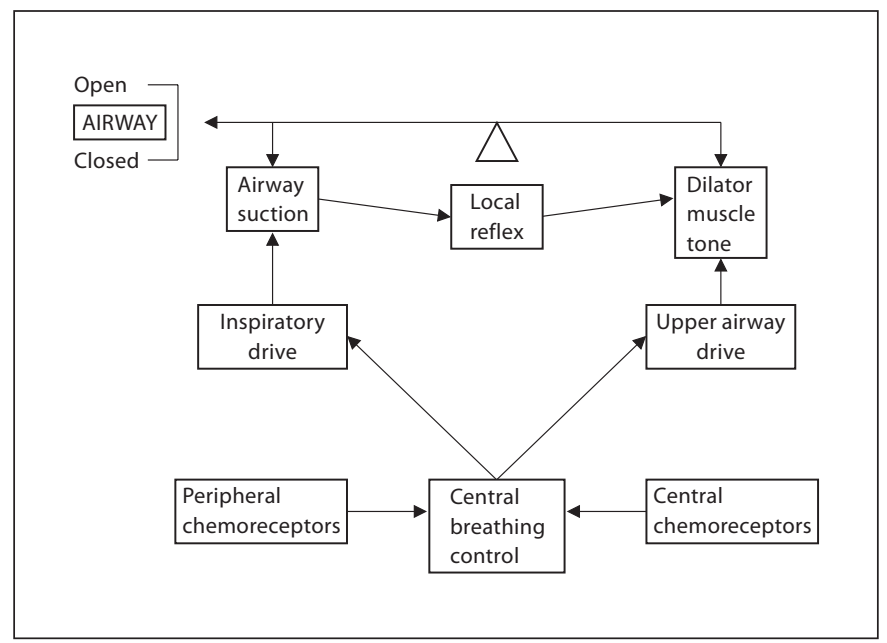

Fig. 1. The balance of forces model.

the distance of the hyoid bone to the mandibular plane. This may indicate that the anatomy of the upper airway determines Pcrit. There are, however, also other indications that cross sectional area of the upper airway, especially during inspiration, influences the Pcrit and UA collapsibility. Indeed specific stimulation of the motor part of the hypoglossal nerve during inspiration not only lowers the apnoea/hypopnoea index (AHI) in OSA patients, but also significantly decreases the Pcrit [19]. This is a very important observation since it implies that all local interventions that increase cross sectional area of the UA at the end of the inspiration have the potential to improve the sleep apnoea syndrome by lowering the Pcrit. It has also been shown that Pcrit may be related to lung volume. Upper airway size increases at higher lung volumes [20, 21]. The lung volume dependence of the upper airway size may also be greater in OSA patients. Reductions in functional residual capacity may increase pharyngeal collapsibility through reductions in tracheal traction on the pharyngeal segment. One mechanism by which CPAP may work is by increased lung volume [22].

\section{Expiratory Collapse}

Studies using endoscopic control of the UA size have demonstrated that the complete collapse of the upper airway in OSA patients occurs at the end of the expiration preceding the apnoeic event [23]. This was also seen in the UA imaging studies [24]. We recently used the forced oscillation technique (FOT) to study the airway impedance during sleep in OSA patients [25-28]. The impedance often rises during inspiration but always drops dur- 
Table 2. Determinants of loop gain according to sleep stages

\begin{tabular}{lll}
\hline & Stage 1-2 & Stage 3-4 \\
\hline Plant gain & increased & increased \\
$\quad$ Metabolic rate & $\downarrow$ & $\downarrow$ \\
$\mathrm{PaCO}_{2}$ & $\uparrow$ & $\uparrow$ \\
Controller gain (chemoreceptors) & decreased & decreased++ \\
Loop gain (overall gain) & increased & decreased \\
\hline
\end{tabular}

ing the following expiration until collapse occurs during the end of an expiration (with Zrs amounting to the level observed during the apnoea). This clearly confirms the observations from the imaging studies, where cross sectional area of the upper airway is seen lowest at the end of the expiration.

\section{Modeling of the Expiratory Collapse}

Since the expiratory phase preceding the apnoea is crucial in the pathogenesis and the understanding of the UA collapse, we tried to model the upper airway during this phase using finite element techniques [29]. The 3D model was constructed by converting a CT scan to a computer-aided design model. The boundary conditions for this analysis approximate a normal expiration, where the displacement of the upper airway wall is limited. At the inlet a transient velocity is defined, while at the outlet a transient pressure is defined. All data are based on in-patient measurements obtained during sleep studies. By applying realistic boundary conditions and material properties, it was possible to generate a model that is in agreement with data obtained with the FOT. Clearly they correlate with the FOT data and confirm that after an initial rise in velocity during expiration, velocity drops and wall collapse occurs, which is almost complete at the end of the expiration.

\section{Overall Pathogenic Model}

When all data are taken into account, it is quite clear that OSA patients have a smaller and more collapsible airway. The airway is most at risk for complete collapse at the end of an expiration, where the tissue pressure may be larger than the intra-luminal pressure. However, it is also clear that a larger airway is associated with less collapsibility or lower Pcrit. Anatomical predisposition correlates with Pcrit [18] and artificial enlargement of the UA during inspiration also shifts the pressure-flow curve to the left [30]. The UA collapse, partially determined by the cross sectional area during inspiration, finally occurs at the end of an expiration. This process can be modelled for individual patients based on their anatomic properties obtained by UA CT and UA flow pressure profiles obtained during sleep [31,32]. With the same model it can also be predicted that prolongation of expiratory time promotes collapse. Younes et al. [34] assessed the degree of respiratory control system instability by quantifying loop gain, which is the ratio of a corrective response (ventilation) to a disturbance (ventilatory perturbation that instigated the response). Loop gain is an engineering term used to describe the overall gain of any system controlled by feedback loops [33, 34]. A high-gain system responds quickly and vigorously to a perturbation, whereas a low-gain system responds more slowly and weakly. The 2 primary variables influencing loop gain are known as controller gain and plant gain, and both are important in ventilatory stability. The relative impact of loop gain with reference to sleep stage is shown in table 2.

Controller gain is synonymous with chemoresponsiveness or the hypoxic and hypercapnic ventilatory responses. Thus, a high controller gain is generally due to brisk hypercapnic responsiveness. Plant gain largely reflects the effectiveness of a given level of ventilation to eliminate $\mathrm{CO}_{2}$. At loop gain $>1$, respiration is unstable, and periodic breathing tends to occur. Younes et al. [34] found that loop gain was greater in patients with severe OSA than in those with mild OSA [35]. Therefore, with more loop gain and $\mathrm{PCO}_{2}$ dropping for a longer time period below the apnoeic threshold, expiratory time may prolong and collapse may be elicited.

Whether sleep and ventilatory instability play a role in upper airway collapse remains currently under investigation. It has been hypothesised that arousals may promote ventilatory instability and further favour pharyngeal collapsibility [36]. Obstructive sleep disorders develop when the normal reduction in pharyngeal dilator activity at sleep onset occurs in an individual whose pharynx requires a relatively high level of dilator activity to remain sufficiently open. It was pointed out that the polysomnographic picture differs substantially among subjects with the same pharyngeal collapsibility, and even in the same patient at different times, indicating that the type and severity of the disorder is determined to a large extent by the individual's response to the obstruction [37].

It has been suggested that obstructed upper airway can reopen by reflex, without arousal, if chemical drive is allowed to reach a threshold but that this is often preempted by a low arousal threshold. The relation between chemical and arousal thresholds, as well as the lung-tocarotid circulation time and the rate of rise of chemical 
drive during the obstructive event determine the magnitude of ventilatory overshoot at the end of an event and, by extension, whether initial obstructive events will be followed by stable breathing, slow evolving hypopnoeas with occasional arousals or repetitive events [37]. We previously could also show that OSA patients may have a higher chemical drive (hypercapnic ventilatory response) that can contribute to the increased loop gain $[38,39]$. Moreover, cyclic changes in arterial $\mathrm{CO}_{2}$ around the $\mathrm{CO}_{2}$ threshold for activation of upper airway motor neuron activity could lead to an imbalance of forces acting on the pharyngeal airway and favour closure. Treatment with CPAP lowers this $\mathrm{CO}_{2}$ drive over time [40]. Of course, any intervention that stabilises the breathing pattern will ultimately also lower the tendency to collapse. This is the case for acetazolamide, which lowers the $\mathrm{CO}_{2}$ threshold and therefore stabilises the breathing pattern. Acetazolamide is clearly effective for central sleep apnoea $[41,42]$ but can also have some effect in OSA patients.

\section{Interaction between Central and Obstructive Sleep Apnoea}

Central and obstructive events are rarely seen in isolation. The vast majority of patients with OSA also have some central events and vice versa. This observation suggests that the mechanisms responsible for the different types of apnoea must overlap. In order to study the relationship between sleep-induced periodic breathing and the development of occlusive sleep apnoeas, patients with hypersomnia-sleep apnoea were studied [43]. In this important study it was shown that sleep-induced periodic breathing, representing the instability of the system, is primary to the development of OSA. More recently, the relationship between periodic breathing and OSA was confirmed. The obstruction is, however, only manifested in subjects susceptible to upper airway atonicity and narrowing [44].

A cause and effect relationship between central and obstructive apnoeas is given by the (frequent) occurrence of mixed apnoeas, characterised by a period of decreased central drive followed by an obstructed breath. It is our experience that central apnoeas without subsequent obstruction are less frequent than mixed apnoeas, in a general referral population with suspicion of sleep-related breathing disorders. A high index for central apnoeas, with a low index for obstructive apnoeas, is encountered in only a limited number of subjects. This probably reflects the large scatter in upper airway collapsibility and the tendency to collapse in most (even healthy) subjects
[45] when the drive to the inspiratory muscles, and especially the upper airway muscles, is reduced at the nadir of periodic breathing. Upper airway muscle activation due to increasing $\mathrm{PaCO}_{2}$ may come behind the activation of the chest wall muscles. This represents an obvious cause of upper airway collapse [46]. During unstable breathing with waxing and waning of respiration, continuous changes in $\mathrm{PaCO}_{2}$ may trigger obstructive breaths by this particular type of mechanism. The decreased upper airway activation does not necessarily lead to complete collapse. It was shown in normal volunteers that total pulmonary resistance may be at its highest at the nadir of periodic changes (induced by breathing hypoxic mixtures) without complete collapse of the upper airway [47]. There was also a significant linear relationship between resistance and inverse tidal volume. Therefore, obstructive hypopnoeas may also be triggered by periodic breathing.

The same correlation between upper airway collapse and breathing patterns was studied in 10 healthy preterm infants, in which periodic breathing frequently occurs. Pulmonary resistance at half-maximal tidal volume, inspiratory time, expiratory time and mean inspiratory flow were derived from computer analysis of 5 cycles of periodic breathing. In $80 \%$ of infants, periodic breathing was accompanied by completely obstructed breaths at the onset of ventilatory cycles. The site of obstruction was located within the pharynx [48]. Some authors have thought that the collapsibility of the upper airway in itself triggers irregularities in the breathing pattern and central apnoeas. Eight patients with idiopathic central sleep apnoea were compared to 8 weight-matched, snoring control subjects. Patients with central apnoea, when compared with control subjects, exhibited markedly increased specific pharyngeal 'compliance', increased change in pharyngeal area from FRC to RV and a larger pharyngeal area at FRC. It was therefore concluded that increased pharyngeal compliance and lung volume dependence may play a role in the aetiology of central apnoeas [49]. The number of patients studied is small, taking into account the large scatter in upper airway collapsibility in 'normal' subjects [45]. It remains, however, a very attractive hypothesis to suppose a relationship between upper airway mucosal stimulation during (near) collapse and the occurrence of central apnoea.

It was also shown that the genioglossus muscle responds to negative airway pressure by reflex activation during wakefulness [50]. This reflex activation is reduced or lost during NREM sleep [51]. One could, however, based on this data, also speculate that decreased ventila- 
tion, as it occurs during periodic breathing, goes along with less stimulation of the genioglossal muscle, since the corresponding negative pressure stimulus is equally reduced.

Elderly people, with oscillations in upper airway resistance, have more apnoeas and hypopnoeas than those subjects without such oscillations. The oscillations in upper airway resistance produce a fluctuating mechanical limitation of ventilation which may contribute to periodic breathing [52].

Another factor that may prevent occlusive breaths due to instability in the breathing pattern is the short-term post-stimulus potentiation, or after-discharge, following a brief hypoxic stimulus. After-discharge in these circumstances prevents ventilation from dropping below baseline, when hyperoxia and hypocapnia follow the hyperventilation phase, induced by the initial hypoxia. It was observed that patients with OSA have reduced afterdischarge and therefore are prone to more unstable breathing [53].

Recently, upper airway patency was studied during central apnoea using fibre-optic nasopharyngoscopy [54, 55]. During induced hypocapnic central apnoea, gradual progressive pharyngeal narrowing occurred. This was even more pronounced, with complete pharyngeal occlusion, in patients with known sleep apnoea or hypopnoea. We also obtained indications for airway closure during central apnoea, based on measurements of critical closure pressure [56] and with FOT [26]. We can speculate that an 'early' arousal will terminate central apnoea, while a 'delayed' arousal will allow the central apnoea to develop into a mixed apnoea. Chemical drives may also play a role in this interaction. We recently could demonstrate that $\mathrm{CO}_{2}$ drive correlates with event time in central apnoea and with apnoea duration in OSA. This confirms that high chemical drives promote instability in the breathing pattern, but also suggests that high drives may shorten the apnoea duration in case of upper airway collapse [39].

\section{Therapeutic Consequences in OSA}

The choice of the therapy and also the introduction of new therapies depends on the insight into the pathogenetic mechanisms in general and, more importantly, for the patient under consideration. For patients with milder forms of OSA, where alternative treatment options for nCPAP can be considered, it might be worthwhile to obtain insight into the critical closing pressure, the site of collapse and the UA anatomy. Then, a more substantiated choice of local therapy can be made. At present, we are able to model the upper airway from individuals, so that we can predict the outcome of local interventions [3]. Such models, however, still need larger scale evaluation, but may represent a very intriguing new approach that can improve therapeutic outcomes.

\section{Central Sleep Apnoea}

There is evidence to suggest that there are a number of phenotypic traits that predispose an individual to the development of CSA. This is generally related to high loop gain (idiopathic CSA, CSR), prolonged circulation time (CSR) or defective effector organs (hypercapnic respiratory failure). There is accumulating evidence that CSA should be considered as the end of a spectrum [57]. Mostly, CSA occurs as the hallmark of unstable breathing during sleep brought about by an overall increase in loop gain (especially in light sleep stages) and the unmasking of a $\mathrm{CO}_{2}$ threshold. Arousal following central apnoeas acts as an amplification of the instability. They are responsible for sleep fragmentation and hypersomnolence during the day. Idiopathic CSA is a relatively uncommon disorder seen at sea level, which shares the same mechanisms as present in CSR, and both can be classified as high loop gain disorders. Both tend to have low $\mathrm{PaCO}_{2}$ levels, even during wakefulness, and occur primarily during NREM sleep. CSA can also occur in specific pathologies, such as chronic heart failure (CHF) and (posttraumatic) brain lesions, that are associated with CSR. Decreased chemical drive and/or failing respiratory muscle function are associated with CSA and usually also with ongoing hypoventilation during wakefulness, characterised by chronic daytime hypercapnia.

Almost all studies have shown that patients with CHF may develop unstable breathing during sleep. However, not all patients develop an abnormal breathing pattern and those doing so present with central as well as obstructive apnoeas [58-60]. Almost one third develop more or less pure central apnoeas and one third pure obstructive apnoeas. It is, therefore, worthwhile to consider pathogenetic mechanisms for these phenomena in order to be able to choose the best therapeutic options. It has also been shown that $\mathrm{CHF}$ with unstable breathing during sleep has a worse prognosis [61,62], although not all studies confirm this [63]. Here the question is whether the unstable breathing worsens the cardiac function or whether those patients with the lowest cardiac function are most prone to unstable breathing and therefore have the worst prognosis [64]. Only intervention studies with 
effective therapies can learn whether improving the unstable breathing pattern improves survival.

We will therefore first discuss the possible pathogenetic mechanisms that lead to unstable breathing, with focus on CSR, and the interactions between central and obstructive apnoeas in CHF.

\section{Control System Instability in CSA}

The breathing pattern during sleep highly depends on the mechanisms controlling ventilation $[57,65,66]$. During sleep the so called 'wakefulness' drive disappears and the breathing becomes a purely feedback controlled system. Wakefulness drive means that stimuli related to wakefulness such as emotions, speech, vision, sound and exercise do adapt the breathing pattern in the sense that during wakefulness no apnoeas will occur, since there always remains an additional drive that guarantees a minimal level of ventilation. The set point for breathing at rest during wakefulness is given by the intercept of the metabolic hyperbola and the ventilatory response curve for $\mathrm{CO}_{2}$ (fig. 2). Unloading of $\mathrm{CO}_{2}$ below that set point will displace the metabolic hyperbola to the left. Then, during wakefulness the $\mathrm{CO}_{2}$ response curve will deviate from its linear relationship and present as the so called 'hockey stick'. However, during sleep the $\mathrm{CO}_{2}$ curve can be extrapolated linearly so that, if the $\mathrm{CO}_{2}$ unloading is intense enough, it will cross the $\mathrm{x}$-axis, which means that there is no more ventilation and an apnoea occurs. This intercept with the $\mathrm{x}$-axis represents the so-called $\mathrm{CO}_{2}$ apnoeic threshold. When during sleep the $\mathrm{CO}_{2}$ drops below that $\mathrm{CO}_{2}$ apnoeic threshold an apnoea will occur [67]. Due to the apnoea-related hypoventilation, the $\mathrm{CO}_{2}$ will rise again above the threshold and respiration will resume. This will finally lead to periodic breathing during which apnoeas and breathing periods follow each other. When the $\mathrm{CO}_{2}$ response curve shifts to the left, then the apnoeic $\mathrm{CO}_{2}$ level will lower. This means that more $\mathrm{CO}_{2}$ unloading is needed before the $\mathrm{CO}_{2}$ drops below the threshold. Overall the shift to the left of the $\mathrm{CO}_{2}$ response curve stabilises the breathing pattern. $\mathrm{CO}_{2}$ unloading during sleep and leftward displacement of the metabolic hyperbola occurs due to hyperventilation. So, in a routine clinical setting, all conditions that lead to hyperventilation during sleep will destabilise the breathing pattern.

$\mathrm{CHF}$ is such a condition. Patients with CHF often develop pulmonary congestion that will lead to stimulation of intrapulmonary receptors that stimulate ventilation [68-70]. Pulmonary congestion also can lead to ventilation-perfusion mismatch with low V/Q units responsible for hypoxaemia. Low mixed venous $\mathrm{PO}_{2}$ is often associ-

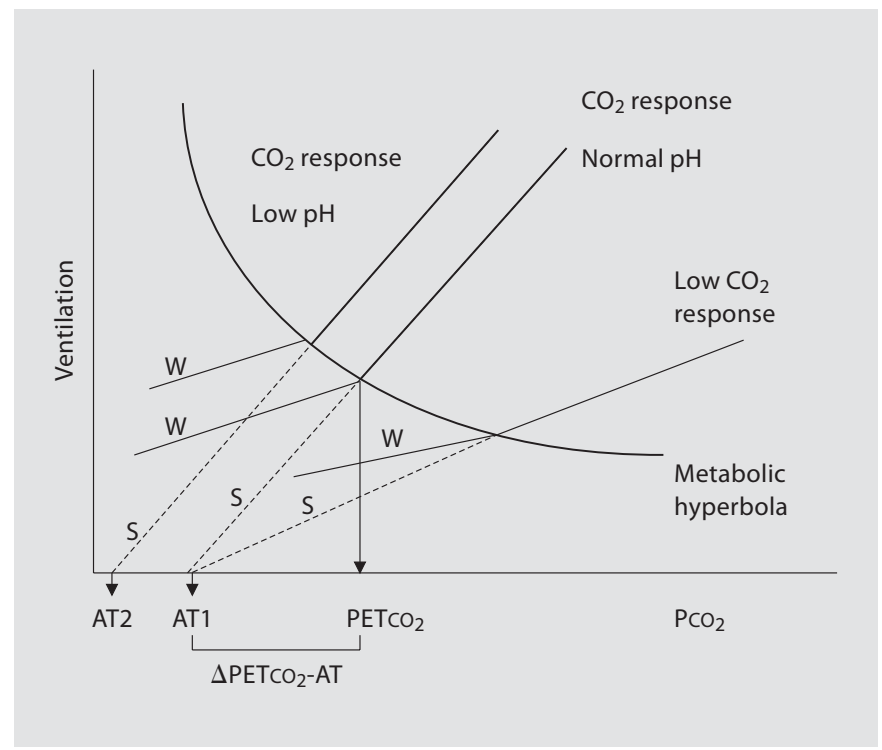

Fig. 2. Hypercapnic ventilatory response curves (HCVR) for different degrees of sensitivity given for wakefulness (W) and sleep (S). During sleep the HCVR curves can be linearly extrapolated so that ventilation will stop at the intercept with the $\mathrm{x}$-axis. The intercept is called the apnoeic threshold for $\mathrm{CO}_{2}$ (AT). Treatment with acetazolamide may shift the $\mathrm{CO}_{2}$ response curve to the left which also shifts the AT to the left (AT1 becomes AT2). When the $\mathrm{CO}_{2}$ threshold is located at AT2 the breathing becomes more stable since it takes more hyperventilation before the $\mathrm{PCO}_{2}$ drops below the threshold.

ated with CHF and will also lead to hypoxaemia. Hypoxaemia will stimulate ventilation by activation of the peripheral chemoreceptors (carotid bodies). The degree of the hypoxic ventilatory response determines the amount of hyperventilation that is associated with hypoxaemia. The hypoxic ventilatory response is mainly genetically determined. It therefore explains partially the variability among patients in the degree of hyperventilation and the associated hypocapnia. It has also been shown that patients with CSA show no rise in $\mathrm{PETCO}_{2}$ from wakefulness to sleep and therefore have their eupnoeic $\mathrm{PCO}_{2}$ closer to the threshold $\mathrm{PETCO}_{2}$ [71]. PETCO $_{2}$ may also be variable over time which explains night-to-night alterations in sleep apnoea [72]. The instability can also be amplified by a diminished cerebrovascular response to $\mathrm{PETCO}_{2}$, especially to hypocapnia. The compromised cerebrovascular reactivity to $\mathrm{CO}_{2}$ may increase instability because of overshooting but especially also undershooting during hypocapnia [73]. Increased ventilatory responses for $\mathrm{CO}_{2}$ on the other hand have also been shown in CHF patients with CSA $[74,75]$ leading to more unstable breathing. Careful 
examination of the respiratory pattern in idiopathic CSA suggests that other mechanisms must be involved as well. A pure cycling of chemoreceptor-mediated respiratory output would yield a gradual waxing and waning of ventilation, with an apnoea or hypopnoea at the nadir as is seen in CSR. In idiopathic CSA, the respiratory pauses are terminated with an abrupt, large breath, not with a gradual increment in ventilation. This pattern strongly suggests that the mechanisms involved in respiratory switching (expiration to inspiration) are affected by this disorder [76]. The long expiratory pause that characterises these central apnoeas seems to be a failure of the expiratory-toinspiratory switch, which may be influenced not only by the chemoreceptors but also other mechanisms as well (lung volume, chest wall mechanoreceptors, blood pressure). How these inputs individually contribute to this cycling respiratory pattern is unclear [77].

\section{Global Model for CSA}

All the above mentioned factors can be integrated into a global model. Also some mathematical models have been developed, taking into account all the factors influencing breathing pattern generation. The occurrence of unstable breathing and periodic breathing depends on the quantitative relationships among the elements of the control systems and certain crucial parameters, such as controller gains, set points and circulation time. Prolongation of the information transfer, due to lengthened circulation time, and increased controller gain and set points make periodic breathing more likely to occur. Occasionally the disturbance is sufficiently great to produce continuous periodic breathing, but more often periodic breathing and the occurrence of central apnoeas is transient. The number and the length of the apnoeas is an indication for the tendency of the system for instability [78]. There are, however, also still other factors involved. Metabolic rate can affect the stability of the response of the system: lower metabolic rates result in increases in the number of apnoeic cycles, when the system is disturbed. Also a shift in the controller operating point during sleep with an increase in $\mathrm{PaCO}_{2}$ can enhance the instability. Gas store changes are accelerated by the proportionally higher amount of $\mathrm{CO}_{2}$ expelled at a given ventilation rate when $\mathrm{PaCO}_{2}$ is higher. In fact, during sleep, metabolic rate declines and $\mathrm{PaCO}_{2}$ rises, while chemoreceptor gains decline as mentioned above, but their inter-subject variability may be high. It is the final interaction between all these factors that, in the end, determines the breathing pattern (table 1). During light sleep the overall result is mainly an increase in overall gain, whereas during slow- wave sleep, due to a further decline in chemoreceptor gain, the overall gain declines. This explains why the most unstable breathing patterns are observed immediately when falling asleep.

Periodic breathing can be simulated by mathematical models. They include the effect of chemical stimuli during sleep on both chest wall and upper airway muscle activity [79]. These models indicate that obstructive as well as central apnoeas can be due to control system instability. Central apnoeas increase the likelihood of obstructive apnoeas, whereas obstructive apnoeas tend to aggravate the control instability [46]. The interaction between central and obstructive apnoeas is therefore very likely and confirmed by many clinical observations.

\section{Interaction between Central and Obstructive Apnoeas in Chronic Heart Failure}

Obstructive apnoeas have clearly more cardiovascular effects since the negative intra-thoracic pressure swings will compromise the left ventricular function. However, it might well be that irregular breathing (and thus central apnoeas) will promote upper airway collapse and thus obstructive apnoeas. Whether apnoeas in patients with congestive heart failure are central or obstructive may depend on the characteristics of the individual's upper airway (size, collapsibility), with obstructive events potentially resulting from decreased upper airway muscle tone at the nadir of the respiratory cycle in an individual with a susceptible airway [77]. It could be shown that prolongation of the expiratory time, as it occurs during a central apnoea, promotes the upper airway to collapse. Patients with already elevated Pcrit will definitely close their upper airway if the expiratory time is prolonged during a central apnoea. Some are still capable of reopening their airway when respiration resumes, but many, because of lack of coordination between upper airway dilators and inspiratory muscle activation or because of bridging at the mucosa level, will not be able to reopen their airways. This means that the prolongation of the expiratory time combined with an already relatively increased Pcrit predisposes some CHF patients not only to CSA but also to OSA or their combination.

\section{Obesity Hypoventilation Syndrome}

OHS is commonly defined as a combination of obesity $\left(\mathrm{BMI} \geq 30 \mathrm{~kg} / \mathrm{m}^{2}\right.$ ) and awake arterial hypercapnia $\left(\mathrm{PaCO}_{2}>45 \mathrm{~mm} \mathrm{Hg}\right)$ in the absence of other known causes 
of hypoventilation [80]. Patients may demonstrate a spectrum of findings: episodes of obstruction, hypoventilation or sustained obstructive hypoventilation due to partial upper airway obstruction [81]. We do not know why some obese patients develop OHS, while others do not, nor do we fully understand the pathogenesis of OHS, although it is almost certainly multifactorial in nature [82]. Some authors suggest that OHS is a mixed disorder of 'can't breathe' (unable to overcome impediments to breathing resulting from derangements in lung function or the performance of the respiratory muscles) and 'won't breathe' (decreased ventilatory drive disorder) [83-85]. Ventilatory muscle dysfunction, abnormal load responsiveness, increased respiratory work and $\mathrm{CO}_{2}$ production, impaired central respiratory drive and repeated airway occlusion during sleep are all possible pathophysiological components in this entitity, but the precise contribution of each remains to be fully clarified [ 81,82 , $86,87]$. Different responses to CPAP or non-invasive positive pressure ventilation (NIPPV) might reflect an intriguing possibility: the weight of the different pathophysiological mechanisms may vary in individuals with OHS. It seems that in some patients, severe obstructive sleep apnoea syndrome might be a major contributor to OHS pathophysiology, with respiratory system mechanics playing only a minor role. These patients could be successfully treated with long-term CPAP. On the other hand, other patients might stand out as having moderate or severe restrictive pulmonary defects and considerable nocturnal desaturation with low AHI values. These patients would require long-term NIPPV $[82,88]$.

\section{Ventilatory System Mechanics}

Obesity acts as a mass load on the respiratory system [89], which implies both a weight placed on the respiratory apparatus as well as an increase in respiratory inertance $[90,91]$. This leads to a significant reduction in total lung capacity, vital capacity, functional residual capacity, and increases in residual volume have been shown [92]. The fat deposit in the chest wall can modify the respiratory mechanisms and can lead to a threefold increase in the work of breathing [93]. Decreases in chest wall and lung parenchymal compliance, increased lung resistance and inspiratory muscle strength have been observed [94, 95]. As a result, OHS patients must maintain an increased oxygen cost of breathing (15\% compared to 3\% in nonobese subjects), which may result in a relative state of respiratory muscle fatigue $[93,96,97]$. Maximal voluntary ventilation, a measure of ventilatory endurance, is reduced in simple obesity and further reduced in OHS [80,
93]. Patients with OHS also have a higher upper airway resistance both in the sitting and supine positions, when compared to patients with moderate-to-severe OSA with similar degrees of obesity and control subjects [98]. The role of diaphragmatic weakness in the pathogenesis of this disorder remains uncertain, because patients with OHS can generate similar transdiaphragmatic pressures at any level of diaphragmatic activation compared to eucapnic obese subjects [96]. Pankow et al. [99] have shown that NIPPV unloads the inspiratory muscles in patients with OHS. These results emphasize the role of respiratory muscle fatigue in OHS.

However, it does not appear that obesity is the only determinant of hypoventilation as only a minority of morbidly obese patients develop chronic hypercapnia $[100,101]$.

\section{Control of Breathing}

Other determinants of hypoventilation include a blunted central responsiveness to hypercapnia and hypoxia $[38,102]$. Patients with OHS can achieve eucapnia during voluntarily hyperventilation, implying that impairments in respiratory system mechanics alone do not explain the hypoventilation [86]. Also, the mouth occlusion pressure (P0.1 response) is higher than seen in nonobese patients [96]. The slope of the hypercapnic ventilatory response is $<1 \mathrm{l} / \mathrm{min} / \mathrm{mm} \mathrm{Hg}$ in OHS, $1.5-2.51 / \mathrm{min} /$ $\mathrm{mm} \mathrm{Hg}$ in eucapnic obese individuals and $2-31 / \mathrm{min} / \mathrm{mm}$ $\mathrm{Hg}$ in healthy subjects $[38,103,104]$. The decrease in ventilatory response is attributed to an inadequate increase in tidal volume as a result of a blunt neural response to hypercapnia $[89,102]$, and has been demonstrated to improve with CPAP or NIPPV $[105,106]$. The hypoxic ventilatory response is also blunted in subjects with OHS. This abnormality is, however, not familial and improves with treatment as well $[107,108]$.

An intriguing component of OHS pathogenesis concerns the metabolic consequences of obesity and its effect on ventilatory control. Leptin acts on the central respiratory centres to stimulate ventilation, whereas leptin deficiency has been associated with hypoventilation [109]. In obese humans, very high levels of leptin have been found that do not seem to suppress appetite, suggesting that human obesity may be a leptin-resistant state. In some obese subjects central leptin resistance may lead to depressed ventilatory drive and, hence, OHS [110]. Yee et al. [87] demonstrated that regular use of non-invasive ventilation reduces leptin in OHS, although evidence is controversial [111]. Differences in study results can be explained by the exclusion of patients with 
OSA, since serum leptin levels are lower in patients with OHS without OSA [111].

\section{Obstructive Sleep Apnoea}

Approximately $90 \%$ of OHS patients have underlying OSA [80]. OSA could predispose to day time hypercapnia by causing nocturnal hypoxaemia [112] and sleep fragmentation [113] that, in turn, impair mass load compensation thereby predisposing obese patients to hypercapnia. Loss of the so-called normal $\mathrm{CO}_{2}$-response to apnoea that protects against the development of hypercapnia by stimulating respiratory compensation for each apnoea during the inter-apnoea period is thought to predispose to daytime hypercapnia in patients with OSA $[114,115]$. Patients with these concurrent syndromes may be caught in a vicious circle, which may lead to more severe exposure to hypoxaemia and hypercapnia and further attenuation of the ventilatory response [80]. The remaining $10 \%$ of patients with OHS have an $\mathrm{AHI}<5$. The sleep-disordered breathing in this subset of patients has been labelled as sleep hypoventilation and is defined as an increase in $\mathrm{PaCO}_{2}$ during sleep by $10 \mathrm{~mm} \mathrm{Hg}$ above wakefulness or significant oxygen desaturation that is not explained by obstructive apnoeas or hypopnoeas [116].

\section{Model Combining Sleep-Disordered Breathing,}

Central Respiratory Drive and Renal Buffering

The role of OSA in the pathogenesis of hypoventilation has been established by the resolution of hypercapnia in the majority of patients with OHS treated with CPAP or bi-level positive airway pressure without any significant change in BMI. There is pathophysiologic basis behind how severe OSA, as measured by AHI, could lead to hypercapnia [117-119]. In patients with OSA, the minute ventilation during sleep does not decrease due to the large increase in the minute ventilation between the obstructive respiratory events. Obstructive apnoeas can, however, lead to acute hypercapnia if the duration of the inter- event hyperventilation is inadequate to eliminate the accumulated $\mathrm{CO}_{2}$ [119]. In very severe cases of OSA, there is not much time left to increase the minute ventilation between the obstructive events, leading to significant nocturnal hypercapnia. This acute hypercapnia causes a small increase in serum bicarbonate level that is not corrected before the next sleep period if the time constant of bicarbonate excretion is longer than that of $\mathrm{CO}_{2}$. The elevated bicarbonate level blunts the ventilatory response to $\mathrm{CO}_{2}$ from its initial value by reducing the change in hydrogen ions for a given change in $\mathrm{CO}_{2}$ and would ultimately result in a higher wake $\mathrm{CO}_{2}$ level $[100,117]$.

\section{Conclusions}

In summary, upper airway mechanics in sleep-disordered breathing encompasses a wide range of distinct yet interrelated mechanisms that lead to substantial pathology. The pathophysiology of the various forms of sleepdisordered breathing varies greatly.

For obstructive apnoea, pharyngeal anatomy, upper airway muscle responsiveness, arousal threshold and loop gain may all contribute to apnoea presence and severity. For central apnoea, many mechanisms can be involved, but most contribute to the increase in the overall gain of the controller system and to the circulation time. OHS results from complex interactions, among which are increased work of breathing related to obesity, normal or diminished ventilatory drive, various associated sleep breathing disorders and neurohormonal changes such as leptin resistance. As outlined in this review, many factors, alone or in combination, can contribute to the development of sleep-disordered breathing and suggest a heterogeneous pallet of clinical presentations, rather than a single disease entity. Knowledge of common patterns of sleep-disordered breathing may help to identify patients and guide therapy.
References

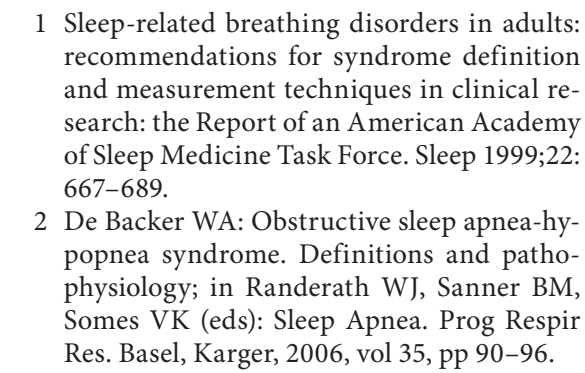

Sleep-related breathing disorders in adults recommendations for syndrome definition of Sleep Medicine Task Force. Sleep 1999;22: 667-689. (eds): Sleep Apnea. Res. Basel, Karger, 2006, vol 35, pp 90-96.
-3 De Backer JW, Vanderveken OM, Vos WG, Devolder A, Verhulst SL, Verbraecken JA, Parizel PM, Braem MJ, Van de Heyning PH, De Backer WA: Functional imaging using computational fluid dynamics to predict treatment success of mandibular advancement devices in sleep-disordered breathing. J Biomech 2007;40:3708-3714.

-4 Schwab RJ, Gefter WB, Hoffman EA, Gupta KB, Pack AI: Dynamic upper airway imaging during awake respiration in normal subjects and patients with sleep disordered breathing. Am Rev Respir Dis 1993;148:1385-1400. 
-5 Schwab RJ, Gupta KB, Gefter WB, Metzger LJ, Hoffman EA, Pack A: Upper airway and soft tissue anatomy in normal subjects and patients with sleep-disordered breathing: significance of the lateral pharyngeal walls. Am J Respir Crit Care Med 1995;152:16731689.

66 Schellenberg JB, Maislin G, Schwab RJ: Physical findings and the risk for obstructive sleep apnea: the importance of oropharyngeal structures. Am J Respir Crit Care Med 2000;162:740-748.

7 Schwab RJ, Pasirstein M, Pierson R, Mackley A, Hachadoorian R, Arens R, Maislin G, Pack AI: Identification of upper airway anatomic risk factors for obstructive sleep apnea with volumetric magnetic resonance imaging. Am J Respir Crit Care Med 2003;168: 522-530.

-8 Ciscar MA, Juan G, Martinez V, Ramón M, Lloret T, Mínguez J, Armengot M, Marín J, Basterra J: Magnetic resonance imaging of the pharynx in OSA patients and healthy subjects. Eur Respir J 2001;17:79-86.

$\checkmark 9$ Fogel RB, Malhotra A, Pillar G, Edwards JK, Beauregard J, Shea SA, White DP: Genioglossal activation in patients with obstructive sleep apnea versus control subjects: mechanisms of muscle control. Am J Respir Crit Care Med 2001;164:2025-2030.

-10 Mezzanotte WS, Tangel DJ, White DP: Waking genioglossal electromyogram in sleep apnea patients versus normal controls (a neuromuscular compensatory mechanism). J Clin Invest 1992;89:1571-1579.

$\checkmark 11$ De Backer W: Upper airway reflexes and obstructive sleep apnoea. Eur Respir J 1993;6: 9-10.

-12 Mezzanotte WS, Tangel DJ, White DP: Influence of sleep onset on upper-airway muscle activity in apnea patients versus normal controls. Am J Respir Crit Care Med 1996;153: 1880-1887.

13 Patil SP, Schneider H, Schwartz AR, Smith PL: Adult obstructive sleep apnea: pathophysiology and diagnosis. Chest 2007;132: 325-337.

14 Younes M: Contributions of upper airway mechanics and control mechanisms to severity of obstructive apnea. Am J Respir Crit Care Med 2003;168:645-658.

15 Gleadhill IC, Schwartz AR, Schubert N, Wise RA, Permutt S, Smith PL: Upper airway collapsibility in snorers and in patients with obstructive hypopnea and apnea. Am Rev Respir Dis 1991;143:1300-1303.

-16 Boudewyns A, Punjabi N, Van de Heyning PH, De Backer WA, O’Donnell CP, Schneider H, Smith PL, Schwartz AR: Abbreviated method for assessing upper airway function in obstructive sleep apnea. Chest 2000;118: 1031-1041.

- 17 Malhotra A, Pillar G, Fogel R, Beauregard J, Edwards J, White DP: Upper-airway collapsibility: measurements and sleep effects. Chest 2001;120:156-161.
18 Sforza E, Bacon W, Weiss T, Thibault A, Petiau C, Krieger J: Upper airway collapsibility and cephalometric variables in patients with obstructive sleep apnea. Am J Respir Crit Care Med 2000;161:347-352.

19 Oliven A, O’Hearn DJ, Boudewyns A, Odeh M, De Backer W, van de Heyning P, Smith PL, Eisele DW, Allan L, Schneider H, Testerman R, Schwartz AR: Upper airway response to electrical stimulation of the genioglossus in obstructive sleep apnea. J Appl Physiol 2003;95:2023-2029.

20 Series F, Cormier Y, Lampron N, La Forge J: Influence of lung volume in sleep apnoea. Thorax 1989;44:52-57.

21 Heinzer RC, Stanchina ML, Malhotra A, Jordan AS, Patel SR, Lo YL, Wellman A, Schory K, Dover L, White DP: Effect of increased lung volume on sleep disordered breathing in patients with sleep apnoea. Thorax 2006; 61:435-439.

22 Verbraecken J, Willemen M, De Cock W, Van de Heyning P, De Backer W: Continuous positive airway pressure and lung inflation in sleep apnea patients. Respiration 2001;68: 357-364.

23 Morrell MJ, Arabi Y, Zahn B, Badr MS: Progressive retropalatal narrowing preceding obstructive apnea. Am J Respir Crit Care Med 1998;158:1974-1981.

24 Schwab RJ, Gefter WB, Hoffman EA, Gupta KB, Pack AI: Dynamic upper airway imaging during awake respiration in normal subjects and patients with sleep disordered breathing. Am Rev Respir Dis 1993;148: 1385-1400.

25 Oostveen E, MacLeod D, Lorino H, Farré R, Hantos Z, Desager K, Marchal F; ERS Task Force on Respiratory Impedance Measurements: The forced oscillation technique in clinical practice: methodology, recommendations and future developments. Eur Respir J 2003;22:1026-1041.

26 Vanderveken OM, Oostveen E, Boudewyns AN, Verbraecken JA, Van de Heyning PH, De Backer WA: Quantification of Pharyngeal Patency in Patients with Sleep-Disordered Breathing. ORL J Otorhinolaryngol Relat Spec 2005;67:168-179.

27 Vanderveken O, Oostveen E, Boudewyns A, Verbraecken J, Van de Heyning P, and De Backer W: Expiratory upper airway closure preceding obstructive sleep apnea. Am J Respir Crit Care Med 2005;2:A761.

28 Oostveen E, Vanderveken O, Verbraecken J, De Backer W: Progressive upper airway narrowing occurs during expiration prior to obstructive, central and mixed apneas. Am J Respir Crit Care Med 2005;2:A610.

29 De Backer JW, Vos WG, Verhulst SL, De Backer W: Novel imaging techniques using computer methods for the evaluation of the upper airway in patients with sleep-disordered breathing: a comprehensive review. Sleep Med Rev 2008;12:437-447.
$>30$ Boudewyns A, Punjabi N, Van de Heyning PH, De Backer WA, O’Donnell CP, Schneider H, Smith PL, Schwartz AR: Abbreviated method for assessing upper airway function in obstructive sleep apnea. Chest 2000;118: 1031-1041.

31 De Backer WA: Diagnosis and treatment of sleep apnea using CFD based modelling. PCT/EP2005/010730. 2006 (patent).

32 Vos W, De Backer J, Devolder A, Vanderveken O, Verhulst S, Salgado R, Germonpre P, Partoens B, Wuyts F, Parizel P, De Backer W: Correlation between severity of sleep apnea and upper airway morphology based on advanced anatomical and functional imaging. J Biomech 2007;40:2207-2213.

33 White DP: Pathogenesis of obstructive and central sleep apnea. Am J Respir Crit Care Med 2005;172:1363-1370.

-34 Younes M, Ostrowski M, Thompson W, Leslie C, Shewchuk W: Chemical control stability in patients with obstructive sleep apnea. Am J Respir Crit Care Med 2001;163:11811190.

35 Ryan CM, Bradley TD: Pathogenesis of obstructive sleep apnea. J Appl Physiol 2005;99: 2440-2450.

36 Younes M: Role of arousals in the pathogenesis of obstructive sleep apnea. Am J Respir Crit Care Med 2004;69:623-633.

37 Younes M: Role of respiratory control mechanisms in the pathogenesis of obstructive sleep disorders. J Appl Physiol 2008;105: 1389-1405.

38 Verbraecken J, De Backer W, Willemen M, De Cock W, Wittesaele W, Van de Heyning P: Chronic $\mathrm{CO}_{2}$ drive in patients with obstructive sleep apnea and effect of CPAP. Respir Physiol 1995;101:279-287.

$>39$ Verbraecken J, Willemen M, Wittesaele W, De Cock W, Van de Heyning P, De Backer W: Relationship between $\mathrm{CO}_{2}$ drive and characteristics of apneas in obstructive and central sleep apnea. Respir Physiol 1998;114:185194.

40 Verbraecken J, Willemen M, De Cock W, Wittesaele W, Govaert K, Van de Heyning P, De Backer W: Influence of longterm CPAP therapy on $\mathrm{CO}_{2}$ drive in patients with obstructive sleep apnea. Respir Physiol 2000; 123:121-130.

41 De Backer WA, Verbraecken J, Willemen M, Wittesaele W, De Cock W, Van de Heyning P: Central apnea index decreases after prolonged treatment with acetazolamide. Am J Respir Crit Care Med 1995;151:87-91.

$\checkmark 42$ Verbraecken J, Willemen M, De Cock W, Coen E, Van de Heyning P, De Backer W: Central sleep apnea after interrupting longterm acetazolamide therapy. Respir Physiol 1998;112:59-70.

43 Önal E, Lopata M: Periodic breathing and the pathogenesis of occlusive sleep apneas. Am Rev Respir Dis 1982;126:676-680. 
44 Warner G, Skatrud JB, Dempsey JA: Effect of hypoxia-induced periodic breathing on upper airway obstruction during sleep. J Appl Physiol 1987;62:2201-2211.

45 Wiegand L, Zwillich CW, White DP: Collapsibility of the human upper airway during normal sleep. J Appl Physiol 1989;66:18001808.

46 Longobardo GS, Gothe B, Goldman MD, Cherniack NS: Sleep apnea considered as a control system instability. Respir Physiol 1982;50:311-333.

-47 Önal E, Burrows DL, Hart RH, Lopata M: Induction of periodic breathing during sleep causes upper airway obstruction in humans. J Appl Physiol 1986;61:1438-1443.

-48 Miller MJ, Carlo WA, Difiore JM, Martin RJ: Airway obstruction during periodic breathing in premature infants. J Appl Physiol 1988;64:2496-2500.

-49 Bradley TD, Brown IG, Zamel N, Phillipson EA, Hoffstein V: Differences in pharyngeal properties between snorers with predominantly central sleep apnea and those without sleep apnea. Am Rev Respir Dis 1987;135: 387-391.

-50 Horner RL, Innes JA, Murphy K, Guz A: Evidence for reflex upper airway dilator muscle activation by sudden negative airway pressure in man. J Physiol 1991;436:15-29.

51 Wheatley JR, Mezzanotte WS, Tangel DJ, White DP: Influence of sleep on genioglossus muscle activation by negative pressure in normal men. Am Rev Respir Dis 1993;148: 597-605.

-52 Hudgel DW, Devadatta P, Hamilton H: Pattern of breathing and upper airway mechanics during wakefulness and sleep in healthy elderly humans. J Appl Physiol 1993;74: 2198-2204.

53 Georgopoulus D, Giannouli E, Tsara V, Argiropoulou P: Respiratory short-term poststimulus potentiation (after-discharge) in patients with obstructive sleep apnea. Am Rev Respir Dis 1992;146:1250-1255.

-54 Badr MS, Toiber F, Skatrud JB, Dempsey $\mathrm{J}$ : Pharyngeal narrowing/occlusion during central sleep apnea. J Appl Physiol 1995;78: 1806-1815.

-55 Sankri-Tarbichi AG, Rowley JA, Badr MS: Expiratory pharyngeal narrowing during central hypocapnic hypopnea. Am J Respir Crit Care Med 2009;179:313-319.

56 De Backer W, Boudewyns A, Willemen M, De Cock W, Van de Heyning P: Intraluminal pressures during central apnea compared to critical closing pressures. Sleep Res 1996;25: 231.

-57 De Backer WA: Central sleep apnoea, pathogenesis and treatment: an overview and perspective. Eur Respir J 1995;8:1372-1383.

58 Javaheri S, Parker TJ, Liming JD, Corbett WS, Nishiyama H, Wexler L, Roselle GA: Sleep apnea in 81 ambulatory male patients with stable heart failure. Types and their prevalences, consequences, and presentations. Circulation 1998;97:2154-2159.
99 Sin DD, Fitzgerald F, Parker JD, Newton G, Floras JS, Bradley TD: Risk factors for central and obstructive sleep apnea in 450 men and women with congestive heart failure. Am J Respir Crit Care Med 1999;160:1101-1106.

60 Ferrier K, Campbell A, Yee B, Richards M, O’Meeghan T, Weatherall M, Neill A: Sleepdisordered breathing occurs frequently in stable outpatients with congestive heart failure. Chest 2005;128:2116-2122.

61 Ancoli-Israel S, Engler RL, Friedman PJ, Klauber MR, Ross PA, Kripke DF: Comparison of patients with central sleep apnea with and without Cheyne-Stokes respiration. Chest 1994;106:780-786.

62 Ancoli-Israel S, DuHamel ER, Stepnowsky C, Engler R, Cohen-Zion M, Marler M: The relationship between congestive heart failure, sleep apnea, and mortality in older men. Chest 2003;124:1400-1405.

63 Roebuck T, Solin P, Kaye DM, Bergin P, Bailey M, Naughton MT: Increased long-term mortality in heart failure due to sleep apnoea is not yet proven. Eur Respir J 2004;23:735740 .

64 Lanfranchi PA, Somers VK: Sleep-disordered breathing in heart failure: characteris tics and implications. Respir Physiol 2003; 136:153-165

65 Caples SM, Wolk R, Somers VK: Influence of cardiac function and failure on sleep-disordered breathing: evidence for a causative role. J Appl Physiol 2005;99:2433-2439.

66 De Backer WA: Methods and clinical significance of studying chemical drives. Respir Physiol 1998;114:75-81.

67 Dempsey JA, Skatrud JB: A sleep-induced apneic threshold and its consequences. Am Rev Respir Dis 1986;133:1163-1170.

68 Solin P, Bergin P, Richardson M, Kaye DM Walters EH, Naughton MT: Influence of pulmonary capillary wedge pressure on central apnea in heart failure. Circulation 1999;99: 1574-1579.

69 Arzt M, Bradley TD: Treatment of sleep apnea in heart failure. Am J Respir Crit Care Med 2006;173:1300-1308.

70 Pepin JL, Chouri-Pontarollo N, Tamisier R, Levy P: Cheyne-Stokes respiration with central sleep apnoea in chronic heart failure proposals for a diagnostic and therapeutic strategy. Sleep Med Rev 2006;10:33-47.

71 Xie A, Skatrud JB, Puleo DS, Rahko PS, Dempsey JA: Apnea-hypopnea threshold for $\mathrm{CO}_{2}$ in patients with congestive heart failure. Am J Respir Crit Care Med 2002;165:12451250

72 Tkacova R, Wang H, Bradley TD: Night-tonight alterations in sleep apnea type in patients with heart failure. J Sleep Res 2006;15: 321-328.

73 Xie A, Skatrud JB, Khayat R, Dempsey JA, Morgan B, Russell D: Cerebrovascular response to carbon dioxide in patients with congestive heart failure. Am J Respir Crit Care Med 2005;172:371-378.
74 Solin P, Roebuck T, Johns DP, Walters EH, Naughton MT: Peripheral and central ventilatory responses in central sleep apnea with and without congestive heart failure. Am J Respir Crit Care Med 2000;162:2194-2200.

75 Javaheri S: A mechanism of central sleep apnea in patients with heart failure. $\mathrm{N}$ Engl J Med 1999;341:949-954.

76 Younes M: The physiologic basis of central apnea and periodic breathing. Curr Pulmonol 1989;10:265-326.

77 White DP: Central sleep apnea; in Kryger $\mathrm{MH}$, Roth T, Dement WC (eds): Principles and Practice of Sleep Medicine. Philadelphia, Elsevier Saunders, 2005, pp 969-982.

78 Cherniack NS, Longobardo GS: Effect of metabolic rate on the occurrence of periodic breathing; in Issa FG, Suratt PM, Remmers JE (eds): Sleep and Respiration. Wilmington, Wiley-Liss, 1990, pp 167-176.

79 Cherniack NS, Von Euler C, Homma I, Kao FF: Experimentally induced Cheyne-Stokes breathing. Respir Physiol 1979;37:185-200.

80 Olson AL, Zwillich C: The obesity hypoventilation syndrome. Am J Med 2005;118:948956.

81 Berger KI, Ayappa I, Chatr-Amontri B, Marfatia A, Sorkin IB, Rapoport DM, Goldring RM: Obesity hypoventilation syndrome as a spectrum of respiratory disturbances during sleep. Chest 2001;120:1231-1238.

-82 Pérez de Llano LA, Golpe R, Piquer MO, Racamonde AV, Caruncho MV, Lopez M, Farinas MC: Clinical heterogeneity among patients with obesity hypoventilation syndrome: therapeutic implications. Respiration 2008;75:34-39.

83 Cherniak NS: What causes hypercapnia? Won't breathe, can't breathe or something in between? Respiration 2008;75:251-252.

84 Martin TJ, Sanders MH: Chronic alveolar hypoventilation: a review for the clinician. Sleep 1995;18:617-634.

85 Teichtahl H: The obesity-hypoventilation syndrome revisited. Chest 2001;120:336-339.

86 Leech J, Önal E, Aronson R, Lopata M: Voluntary hyperventilation in obesity hypoventilation. Chest 1991;100:1334-1338.

87 Yee BJ, Cheung J, Philpps P, Banerjee D, Piper AJ: Treatment of obesity hypoventilation syndrome and serum leptin. Respiration 2006;73:209-212.

88 Pérez de Llano LA, Golpe R, Ortiz Piquer M, Veres Racamonde A, Vazquez Caruncho M, Caballero Muinelos O, Alvarez Carro C: Short-term and long-term effects of nasal intermittent positive pressure ventilation in patients with obesity-hypoventilation syndrome. Chest 2005; 128:587-594.

89 Lopata M, Önal E: Mass loading, sleep apnea, and the pathogenesis of obesity hypoventilation. Am Rev Respir Dis 1982;126:640-645.

90 Sharp JT, Henry JP, Sweany SK, Meadows WR, Pietras RJ: Total respiratory system inertance and its gas and tissue components in normal and obese men. J Clin Invest 1964;43: 503-509. 
-91 Case KR, Ortiz K, Brown LK: Sleep-related hypoventilation/hypoxemic syndromes. Chest 2007;131:1936-1948.

$\checkmark 92$ Rubinstein I, Zamel N, DuBarry L, Hoffstein V: Airflow limitation in morbidly obese, nonsmoking men. Ann Intern Med 1990;112:828-832.

-93 Sharp JT, Henry JP, Sweany SK, Meadows WR, Pietras RJ: The total work of breathing in normal and obese men. J Clin Invest 1964;43:728-739.

-94 Thomas PS, Cowen ERT, Hulands G, Milledge JS: Respiratory function in the morbidly obese before and after weight loss. Thorax 1989;4:382-386.

95 Resta O, Foschino-Barbaro MP, Bonfitto P, Talamo S, Legari G, De Pergola G, Minenna A, Giorgino R: Prevalence and mechanisms of diurnal hypercapnia in a sample of morbidly obese subjects with obstructive sleep apnoea. Respir Med 2000;94:240-246.

96 Sampson MG, Grassino K: Neuromechanical properties in obese patients during carbon dioxide rebreathing. Am J Med 1983; 75:81-90.

97 Kress JP, Pohlman AS, Alverdy J, Hall JB: The impact of morbid obesity on oxygen cost of breathing $\left(\mathrm{VO}_{2 \mathrm{RESP}}\right)$ at rest. Am J Respir Crit Care Med 1999;160:883-886.

98 Lin CC, Wu KM, Chou CS, Liaw SF: Oral airway resistance during wakefulness in eucapnic and hypercapnic sleep apnea syndrome. Respir Physiol 2004;139:215-224.

99 Pankow W, Hijjeh N, Schuttler F, Penzel T, Becker HF, Peter JH, von Wichert P: Influence of noninvasive positive pressure ventilation in obese subjects. Eur Respir J 1997; 10:2847-2852.

100 Mokhlesi B, Tulaimat A: Obesity hypoventilation syndrome: prevalence and predictors in patients with obstructive sleep ap nea. Sleep Breath 2007;11:117-124.

101 Laaban JP, Chailleux E: Daytime hypercapnia in adult patients with obstructive sleep apnea syndrome in France, before initiating nocturnal nasal continuous positive airway pressure therapy. Chest 2005;127: $710-715$.
102 Zwillich CW, Sutton FD, Pierson DJ, Greagh EM, Weil JV: Decreased hypoxic ventilatory drive in the obesity hypoventilation syndrome. Am J Med 1975;59:343-348.

103 Rapoport DM, Garay SM, Epstein H, Goldring RM: Hypercapnia in the obstructive sleep apnea syndrome: a reevaluation of the 'Pickwickian syndrome'. Chest 1986;89: 627-635.

104 Berthon-Jones M, Sullivan CE:Time course of change in ventilatory response to $\mathrm{CO}_{2}$ with long-term CPAP therapy for obstructive sleep apnea. Am Rev Respir Dis 1987; 135:144-147.

105 Lin CC: Effect of nasal CPAP on ventilatory drive in normocapnic and hypercapnic patients with obstructive sleep apnoea syndrome. Eur Respir J 1994;7:2005-2010.

106 De Lucas-Ramos P, de Miguel-Diez J, Santacruz-Siminiani A, González-Moro JM, Buendía-García MJ, Izquierdo-Alonso JL: Benefits at 1 year of nocturnal intermittent positive pressure ventilation in patients with obesity-hypoventilation syndrome. Respir Med 2004;98:961-967.

107 Jokic R, Zintel T, Sridhar G, Gallagher CG, Fitzpatrick MF: Ventilatory responses to hypercapnia and hypoxia in relatives of patients with the obesity hypoventilation syn drome. Thorax 2000;55:940-945.

108 Han F, Chen E, Wei H, He Q, Ding D, Strohl KP: Treatment effects on carbon dioxide retention in patients with obstructive sleep apnea-hypopnea syndrome. Chest 2001, 119:1814-1819.

109 O’Donnell CP, Schaub CD, Haines AS, Berkowitz DE, Tankersley CG, Schwartz AR, Smith PL: Leptin prevents respiratory depression in obesity. Am J Respir Crit Care Med 1999;159:1477-1484.

110 Phipps PR, Starritt E, Caterson I, Grunstein RR: Association of serum leptin with hypoventilation in human obesity. Thorax 2002;57:75-76
111 Redolfi S, Corda L, La Piana G, Spandrio S, Prometti P, Tantucci C: Long-term non-invasive ventilation increases chemosensitivity and leptin in obesity hypoventilation syndrome. Respir Med 2007;101:11911195.

112 Weil JV, Byrne-Quinn E, Sodal IE, Filley GF, Grover RF: Acquired attenuation of chemoreceptor function in chronically hypoxic man at high altitude. J Clin Invest 1971;50:186-195

113 Cooper KR, Phillips BA: Effect of shortterm sleep loss on breathing. J Appl Physiol 1982;53:855-858.

114 Mutlu GM, Rubinstein I: The saga of obstructive sleep apnea syndrome and daytime hypercapnia: work in progress. Chest 2005;127:698-699.

115 Berger KI, Ayappa I, Sorkin IB, Norman RG, Rapoport DM, Goldring RM: Postevent ventilation as a function of $\mathrm{CO}_{2}$ load during respiratory events in obstructive sleep apnea. J Appl Physiol 2002;93:917924.

116 Mokhlesi B, Kryger MH, Grunstein RR: Assessment and management of patients with obesity hypoventilation syndrome. Proc Am Thor Soc 2008;5:218-225.

117 Norman RG, Goldring RM, Clain JM, Oppenheimer BW, Charney AN, Rapoport DM, Berger KI: Transition from acute to chronic hypercapnia in patients with periodic breathing: predictions from a computer model. J Appl Physiol 2006;100:17331741

118 Berger KI, Ayappa I, Sorkin IB, Norman RG, Rapoport DM, Goldring RM: $\mathrm{CO}_{2}$ homeostasis during periodic breathing in obstructive sleep apnea. J Appl Physiol 2000; 88:257-264.

19 Ayappa I, Berger KI, Norman RG, Oppenheimer BW, Rapoport DM, Goldring RM: Hypercapnia and ventilatory periodicity in obstructive sleep apnea syndrome. Am J Respir Crit Care Med 2002;166:1112-1115. 